\title{
Inovação, tecnologia e concorrência: uma revisita ao pensamento neoschumpeteriano
}

\author{
Darcy Jacob Rissardi Júnior ${ }^{*}$ \\ Pery Francisco Assis Shikida* \\ Vanessa de Souza Dahmer ${ }^{* *}$
}

\begin{abstract}
RESUMO - Este artigo revisita quatro dos mais destacados autores neoschumpeterianos (Nathan Rosenberg, Richard R. Nelson, Sidney G. Winter e Giovanni Dosi), ressaltando algumas de suas ideias sobre inovação, tecnologia e concorrência, aspectos estes fundamentais para o entendimento das vicissitudes do mundo moderno.
\end{abstract}

Palavras-chave: Revisão. Literatura neoschumpeteriana. Dinâmica econômica.

\section{INTRODUÇÃO}

Os neoschumpeterianos têm "criticado" Schumpeter, seguindo seu próprio conselho, quer dizer, têm se baseado em novas evidências obtidas a partir da investigação empírica. Seguramente os neoschumpeterianos acertaram ao ressaltar aspectos evolutivos e mutantes da organização e o comportamento da empresa. Sua visão da empresa como uma organização que aprende e é inovadora, sua insistência na heterogeneidade das empresas e suas observações sobre os múltiplos vínculos externos de conhecimento e informação das empresas têm dado realismo e plausibilidade à teoria econômica em uma área em que existia o perigo de perder o contato com as realidades do dia-a-dia (RISSARDI JÚNIOR, 2005).

Nesta premissa de estabelecer que as mudanças tecnológicas e as inovações são as mais importantes fontes de crescimento econômico e de perceber a tecnologia e a inovação como um fator estratégico e estrutural das organizações, pretende-se neste trabalho destacar alguns expoentes da corrente neoschumpeteriana, quais sejam: Nathan Rosenberg, Richard R. Nelson, Sidney G. Winter e Giovanni Dosi.

\footnotetext{
* Mestre em Desenvolvimento Regional e Agronegócio pela UNIOESTE-Toledo. Administrador na UTFPRMedianeira. Endereço eletrônico: darcy@utfpr.edu.br

** Doutor em Economia Aplicada pela ESALQ/USP. Professor Associado do Curso de Ciências Econômicas e do Programa de Mestrado em Desenvolvimento Regional e Agronegócio da UNIOESTE-Toledo. Bolsista de Produtividade em Pesquisa do CNPq e Pesquisador do GEPEC - Grupo de Pesquisa em Agronegócio e Desenvolvimento Regional. Endereço eletrônico: pfashiki@unioeste.br

*** Economista. Mestranda em Desenvolvimento Regional e Agronegócio pela UNIOESTE-Toledo. Endereço eletrônico: nessadahmer@yahoo.com.br
} 


\section{RICHARD R. NELSON, SIDNEY G. WINTER}

Nelson e Winter surgem como dois dos mais ilustres expoentes da corrente neoschumpeteriana, que foi denominada de evolucionista. Isto se deve porque, ao longo das duas últimas décadas, estes teóricos construíram uma teoria geral da mudança em Economia baseados na teoria da evolução das espécies (CORAZZA e FRACALANZA, 2004).

Para Nelson e Winter (1996), na análise da dinâmica das firmas, segundo a perspectiva evolutiva, surge a idéia de rotina que se complementa com as de seleção e busca. A seleção faz referência à competência, que escolhe, ao longo do tempo, as melhores rotinas (estratégicas e operacionais) gerando um processo de diferenciação entre firmas em termos de resultados alcançados no mercado. As firmas estabelecem suas estratégias competitivas em função de sua interpretação dos sinais do mercado. Quando percebem que a estratégia adotada ou sua operacionalização já não permitem defrontar-se adequadamente com as condições de competência, empreendem um processo de busca de novas rotinas.

Esta noção de rotina é central, nesta representação evolutiva, uma vez que estaria na base dos comportamentos dos agentes, e em particular das organizações. De acordo com Nelson e Winter (1996), dentro do ambiente seletivo da competição capitalista, a empresa inova para sobreviver mediante regras de padrões de comportamento previsíveis sob a denominação de "rotinas", constituindo-se numa das premissas básicas dessa abordagem.

Nelson e Winter (1996), citados por Maciel (2003, p. 38), esclarecem:

Em nossa teoria evolutiva, estas rotinas fazem o papel que genes jogam em teoria evolutiva biológica. Elas são uma característica persistente do organismo e determinam seu possível comportamento (entretanto comportamento atual também é determinado pelo ambiente): eles são hereditários no sentido de que os organismos de amanhã gerados hoje (por exemplo, construindo uma planta nova) tenham muitas das mesmas características, e eles são selecionáveis no sentido que organismos com certas rotinas podem fazer melhor que outros, e, nesse caso, a sua importância relativa na população (indústria) é aumentada com o passar do tempo.

Complementa Fagerberg (2002, p. 31):

The firms are assumed to follow decision rules (or "routines"), and it is these routines that are the "social equivalent" of genes in biology. Routines determine behaviour (together with impulses from the environment), are heritable (as part of the "organizational memory" of the firm) and selectable (through the fate of the firms that apply them). However, despite the strong inertia emphasised by Nelson and Winter, routines may also change (the equivalent of mutation in biology). 
Ao discutir a relação entre rotinas e inovação, Dantas et al. (2002) alertam que esta proposição de rotinas como descrição do comportamento das empresas não implica um comportamento imutável. Problemas detectados nas rotinas podem pôr em ação rotinas de solução de problemas ou demandar alterações nas próprias rotinas; a introdução de inovações pode implicar o desenvolvimento de novas rotinas ou adaptação das rotinas anteriores. A própria geração de inovações é uma atividade passível de organização em rotinas que consistem em princípios de busca de soluções de problemas por parte dos cientistas, engenheiros e gerentes.

Cumpre dizer que, de acordo com Nelson e Winter (1996), o processo de inovação, ao envolver um alto grau de incerteza, não só antes, como também após sua introdução, gera um contínuo desequilíbrio de mercado, que implica lucros supranormais para os inovadores, imitação ou morte para as firmas não pioneiras, barreiras para os entrantes potenciais e o aparecimento de novos produtos que influenciarão a organização da indústria no que tange à sua relação com fornecedores e clientes.

Para Nelson e Winter (1996), citados por Correia e Cário (2003), a inovação pode percorrer uma trajetória natural a começar por micromudanças, inovações menores, tentativas e erro, correção de falhas, solução de gargalos e ganhos de experiência e prática, começando a sanar os problemas críticos que estão evidentes. O caminho do progresso técnico é fruto das soluções dos problemas cotidianos. Sobre isto Possas (2002, p. 422) enfatiza que:

\footnotetext{
$\mathrm{Na}$ analogia evolucionária proposta por Nelson e Winter são introduzidas as noções básicas de busca de inovações, procedidas pelas empresas a partir de estratégias; e de seleção dos resultados econômicos dessas mesmas inovações, realizadas pelo mercado - o ambiente da seleção por excelência - e, secundariamente, por outras instituições (centros de pesquisa, universidades e etc).
}

O enfoque evolucionista proposto por Nelson e Winter constrói um sistema teórico no qual o progresso técnico se torna endógeno. Para tanto, recorrem a um mecanismo de seleção ex-post pelo mercado das "mutações" tecnológicas (busca) produzidas pelo processo competitivo (KUPFER, 1996). A seleção, o segundo conceito fundamental desta visão, faz com que as melhores rotinas (estratégicas e operacionais) gerem um processo de diferenciação entre firmas em termos dos resultados a serem alcançados no mercado e nas quais estabelecem suas estratégias competitivas em função desta interpretação do mercado.

O papel do mercado neste caso não é o de fornecer sinais, via preços, para induzir o processo inovativo. O mercado atuaria como fornecedor de feedbacks ao processo de geração, 
mas principalmente no sancionamento das inovações, adotando e excluindo produtos e processos produtivos (SALLES FILHO e SILVEIRA, 1990).

Quando as firmas percebem que a estratégia adotada ou sua operacionalização já não lhes permitem se defrontar adequadamente com estas condições de competitividade, empreendem um processo de busca de novas rotinas.

De acordo com Shikida (1997), a concorrência schumpeteriana tende a produzir vencedores e perdedores, em que algumas firmas certamente tirarão maior proveito das oportunidades técnicas do que outras. A tendência a um aumento no grau de concentração ocorrerá à medida que esse processo avançar, posto que o crescimento conferirá vantagens aos vencedores, enquanto o declínio produzirá obsolescência técnica aos perdedores.

O terceiro conceito fundamental nesta visão evolucionista refere-se aos comportamentos de busca, os quais designam processos genuinamente associados a risco. Ao cunhar o conceito de busca, Nelson e Winter rejeitam que a inovação seja simples resultado de análises do tipo custo-benefício. Se as rotinas de busca, materializadas nas atividades de pesquisa e desenvolvimento, são permeadas por um tipo muito especial de incerteza, a inovação passa a ser um processo guiado por uma heurística de busca, com base em experiências prévias, tentativas, sucessos e fracassos (CORAZZA e FRACALANZA, 2004).

Ao assumirem esta concepção para a análise da dinâmica das firmas, estes autores obtêm outros avanços teóricos. Ao ressaltarem o papel das rotinas de comportamento, introduziram o conceito de "trajetórias naturais" que, apesar das diversas críticas geradas, exercem um papel importante na evolução da tecnologia. Desta forma, Nelson e Winter (1996) rompem com os pressupostos metodológicos neoclássicos, particularmente o de equilíbrio, substituído pela noção mais geral de trajetória; e o de racionalidade maximizadora, substituída pelo de racionalidade limitada ou processual (POSSAS, 2002).

Segundo Winter (1986, p. 205):

\begin{abstract}
Além das diferenças intersetoriais na importância relativa das distintas fontes de conhecimento, as atividades produtivas também diferem em uma variedade de outros aspectos relacionados como a facilidade relativa de imitação, o número de bases de conhecimento relevantes para a gerência de uma rotina produtiva, a facilidade com que os êxitos alcançados na ciência básica se traduzem em êxitos na ciência aplicada (e vice-versa), o tamanho típico do compromisso de recursos de um projeto de inovação, etc. Caracterizar os riscos chaves de um ambiente tecnológico particular nestes diversos aspectos equivale a definir um "regime tecnológico".
\end{abstract}

A noção dos regimes tecnológicos se encontra estreitamente vinculada com a visão evolucionista da mudança técnica em nível da empresa. Neste contexto, as opções técnicas 
que enfrenta a empresa não estão determinadas exogenamente; são idiossincráticas, não mecanicamente codificáveis, na medida em que resultam de sua própria experiência e, especialmente, dos sucessos e fracassos de suas ações de busca.

A acumulação de capacidades e de recursos em uma subsidiária não é um processo necessariamente interligado ou de desenvolvimento concomitante ao de outras. Ainda que os recursos fossem exclusivamente repassados por uma unidade da rede corporativa - por exemplo, a matriz - e uma outra procurasse reproduzir identicamente a rotina da primeira, ambas seriam diferentes (GOMES, 2003).

\section{NATHAN ROSENBERG}

Rosenberg (1982) considera as inovações tecnológicas como um processo de aprendizado e tenta identificar os vários tipos de aprendizado e o modo como estes desembocam num padrão maior de atividades que constituem a inovação tecnológica e, ainda, os encadeamentos que ocorrem entre os processos tecnológicos e suas consequências econômicas. Conforme Shikida (1997, p. 25) relata:

Três aspectos importantes foram acentuados por Rosenberg (1969 e 1982): $1^{\circ}$ ) sua argumentação contrapõe-se a determinados postulados neoclássicos, partindo da negação, em especial, da racionalidade maximizadora - a atividade inovativa é realizada sob condições de incerteza, o que não ocorre nos modelos neoclássicos. Ademais, as mudanças nos preços relativos dos fatores de produção não se configuram em um incentivo para as invenções $\left.[\ldots] ; 2^{\circ}\right)$ ficou evidente que o processo de mudança tecnológica envolve relações complexas, onde os resultados não são conhecidos ex-ante e onde a taxa de adoção de uma tecnologia ou mesmo sua direção estão ligadas às expectativas quanto ao futuro do progresso tecnológico; $3^{\circ}$ ) o nível de aprendizado influi diretamente no rumo da mudança tecnológica.

Para Rosenberg (1982), a partir dos conceitos de learning-by-doing (LBD) e learning-byusing (LBU) se permite verificar a possibilidade de separação de processo de inovação tecnológica em dois momentos - geração e difusão. A idéia geral do learning está associada ao processo de aprendizado tecnológico, cujo aperfeiçoamento advém do processo de difusão.

$\mathrm{Na}$ literatura econômica, o conceito de aprendizado está associado a um processo cumulativo através do qual as firmas ampliam seus conhecimentos, aperfeiçoam seus procedimentos de busca e refinam suas habilidades em desenvolver, produzir e comercializar bens e serviços.

Dentre as várias formas de aprendizado, relevantes ao processo de inovação e ao desenvolvimento de capacitações produtivas, tecnológicas e organizacionais, destacam-se as 
formas de aprendizado a partir de fontes internas e externas à empresa. Expõe Martins (2004, p. 31-32) que:

\begin{abstract}
A dinâmica tecnológica, entendida como um processo de adoção contínua de inovações, depende do conhecimento que é acumulado ao longo do tempo pelo processo de aprendizado, que pode ser mediante learning-bydoing (LBD), learning-by-using (LBU), learning-by-searching (LBS) e/ou learning-by-interacting (LBI). O LBD deriva do aprendizado via processo produtivo, que pode surgir mediante a existência de "gargalos" nesse processo. [...] O LBU deriva do aprendizado via uso, que é revertido na melhoria das condições de produção e uso de um produto/serviço. [...] No LBI o aprendizado decorre do fato dos agentes (fornecedores-firmaconsumidores) permitirem a troca de informações, ações conjuntas, divisão de responsabilidades, estabelecimento de código e procedimentos, etc., que resultam em alterações no status quo dos produtos e processos. [...] No LBS há existência de infraestrutura de conhecimento e a presença de mecanismos mais complexos de aprendizagem intra-firma ou inter-firmas.
\end{abstract}

As informações de grande relevância econômica são um importante anúncio para produtos que utilizam novas tecnologias, e a experiência particular do learning pode conter a chave para a melhoria de produtividade em indústrias de alta tecnologia.

À medida que a velocidade do aprendizado e da inovação aumenta, encurta-se o ciclo de vida dos produtos, exigindo uma crescente capacidade de resposta e reacelerando o processo de pesquisa e inovação. Diante disso, as empresas, inseridas dentro do processo produtivo como agente final da inovação, produção e competição, são cada vez mais pressionadas a aprenderem ou se modernizarem (DINIZ, 2001).

Para Rosenberg (1982 e 2004) e Mowery e Rosenberg (1982), as decisões de inovação e investimento envolverão inevitavelmente um relativo grau de incerteza, sendo que o mercado funciona como uma espécie de fornecedor de feedbacks ao processo de geração de novas tecnologias, sancionando ou vetando desenvolvimentos prováveis, o que torna a incerteza uma característica distintiva da atividade inovadora.

De acordo com Mytelka e Smith (2002), Rosenberg (1982), baseado em efeitos interativos entre variáveis, em oposição ao impacto de uma única variável, para explicar o processo de inovação e difusão, envolve uma série de feedbacks entre: (i) pesquisa; (ii) conhecimento científico e tecnológico; (iii) mercado potencial; (iv) invenção; e (v) os vários degraus do processo de produção. Estes modelos enfatizaram a incerteza e a imprevisível natureza dos processos de inovação e realçaram o impacto dinâmico dos clusters inovativos em oposição à invenção isolada.

Como as novas tecnologias entram no mundo em uma condição muito primitiva e com propriedades e características cuja utilidade não pode ser imediatamente apreciada, 
Rosenberg (1995) apresenta algumas dimensões do processo inovativo inter-relacionadas com as incertezas, tais como: potencialidade de uso, inovações complementares, sistemas integrados, soluções de problemas, o teste de necessidades e competição com o passado. É fundamental, então, reconhecer que as incertezas estão no centro das atividades inovadoras para que se possa entender a natureza das inovações, uma vez que é difícil prever, com segurança, quais novos produtos ou serviços se encaixarão nas preferências dos consumidores e como este mercado responderá a esta inserção inovativa (ROSENBERG, 2004).

Rosenberg (2004) enfatiza, ainda, que o choque de uma inovação tecnológica não dependerá somente de seus inventores, mas também da criatividade dos usuários desta nova tecnologia, ou seja:

In thinking about high tech innovation, we tend to be excessively preoccupied with the work of the scientists and engineers whose $R \& D$ activities have created the new technologies in the first place. This is a case of misplaced emphasis. The benefits that can be made to flow from lasers, microprocessors, computers and information technology generally will ultimately depend not only on its inventors, but also on the creativity of the potential users of the new technology (ROSENBERG, 2004, p. 6).

\section{CHRISTOPHER FREEMAN}

Christopher Freeman foi importante ao destacar o papel do conhecimento científico na inovação e sua difusão no âmbito das empresas. Ao contrário do que se supõe em muitos modelos anteriores, o conhecimento científico não é exógeno ao processo inovador, sendo que, cada vez mais, existe uma maior interação entre a ciência e a tecnologia.

Destarte, a inovação dever ser considerada como um processo interativo, em que a empresa, além de adquirir conhecimentos mediante sua própria experiência no projeto dos processos, desenvolvimento, produção e comercialização, aprende constantemente das suas relações com diversas fontes externas.

Neste aspecto se torna de fundamental importância analisar as estratégias tecnológicas a que estão sujeitas as firmas neste processo de inovação, definidas por Freeman (1974) e Freeman et al. (1982) e que se apresenta, segundo a descrição de Camara (1993), em: ofensiva, defensiva, imitativa, dependente, tradicional e oportunista.

A estratégia ofensiva é característica das empresas que buscam a liderança técnica e de mercado. Os processos de P\&D internos são fortes e possuem papel importante na elaboração de estratégias ofensivas e na busca de informações disponíveis em pesquisa básica. São conhecidas por "intensivas em investigação". 
A estratégia defensiva caracteriza as empresas que são avessas ao risco, mas também são intensivas em P\&D. Entretanto, não optam pelo lançamento de um novo produto no mercado, e sim pelo aperfeiçoamento do aparato técnico-legal às inovações introduzidas. Sua preocupação está no fator concorrencial e institucional do mercado, com atenções especiais para as áreas de treinamento, vendas, publicidade e patentes.

A estratégia imitativa é utilizada pelas empresas que não pretendem obter liderança de tecnologia de mercado. Suas necessidades são de aquisição de licenças e know-how para a realização de suas operações. As atividades de $\mathrm{P} \& \mathrm{D}$ são limitadas, restringindo-se a esforços de adaptação diante das condições locais e à otimização do processo, para que os custos não se descolem de seus competidores.

A estratégia dependente é aquela em que a firma não possui atividade de $\mathrm{P} \& \mathrm{D}$, já que há um estabelecimento de relação de dependência institucional e/ou econômica com outras firmas. Como a firma é comumente assessorada pelos clientes ou pela matriz, seus recursos são aplicados na produção e no marketing.

$\mathrm{Na}$ estratégia tradicional, a empresa não possui atividade de P\&D. Seus produtos quase não se modificam, pois a concorrência geralmente não estimula a inovação, o que favorece a consolidação de uma estrutura industrial próxima à de concorrência perfeita ou oligopolizada.

A estratégia oportunista é característica das empresas que são orientadas a ocuparem um nicho de mercado, associada a conhecimentos específicos de produtos para clientes particulares e que depende, basicamente, do feeling de uma pessoa ou grupo de pessoas. Não desenvolve atividade de P\&D.

As estratégias que as firmas adotam e que são abordadas por Freeman mostram que durante o processo de difusão das inovações se produzem novas inovações que transformam e melhoram a inicial, tanto no grau da transformação dos produtos, bem como na velocidade em que é produzida a difusão, e que variam consideravelmente entre as empresas.

De acordo com Correia e Cário (2003), o processo de inovação pode ser estabelecido pela inter-relação entre as firmas e as alternativas de um paradigma tecnológico.

Nas palavras de Castells (2001, p. 77):

Um paradigma econômico e tecnológico é um agrupamento de inovações técnicas, organizacionais e administrativas inter-relacionadas cujas vantagens devem ser descobertas não apenas em uma nova gama de produtos e sistemas, mas também e, sobretudo, na dinâmica da estrutura dos custos relativos de todos os possíveis insumos para a produção. Em cada novo paradigma, um insumo específico ou conjunto de insumos pode 
ser descrito como o "fator-chave" desse paradigma caracterizado pela queda dos custos relativos e pela disponibilidade universal. A mudança contemporânea de paradigma pode ser vista como uma transferência de uma tecnologia baseada principalmente em insumos baratos de energia para uma outra que se baseia predominantemente em insumos baratos de informação derivados do avanço da tecnologia em microeletrônica e telecomunicações.

Freeman (2004) destaca, ainda, a importância do que denomina de "mudança institucional", que se refere ao impacto das modificações na estrutura das empresas e dos elementos de seu entorno sobre o processo inovador e como podem surgir processos de mudanças tecnológicas relativamente ordenadas, a partir da diversidade e das incertezas associadas ao processo de inovação.

\section{GIOVANNI DOSI}

$\mathrm{Na}$ tentativa de explicar os determinantes, procedimentos e as direções da mudança técnica, assim como seus efeitos sobre o desempenho industrial e a mudança estrutural, Dosi (1982) sugere os conceitos de paradigma tecnológico e de trajetórias tecnológicas.

Com efeito, Dosi (1982) usa a noção de paradigma de científico de Thomas Kuhn para entender o desenvolvimento da tecnologia, apoiando-se numa analogia entre ciência e tecnologia. Segundo Dosi et al. (1990, p. 84), paradigma tecnológico pode ser definido "como um padrão técnico-econômico de solução de problemas, baseado em princípios altamente selecionados derivados a priori do conhecimento e experiência".

O trabalho de Dosi (1988), como o de Kuhn, define a inovação como uma atividade de resolução de problemas e de elaboração de procedimentos específicos para a resolução desses problemas, caracterizando-a, segundo Lemos (1999, p. 126), "como a busca, descoberta, experimentação, desenvolvimento, imitação e adoção de novos produtos, processos e novas técnicas organizacionais".

Um paradigma aparece quando existe um consenso a respeito dos conhecimentos científicos pertinentes para se compreender um problema novo. Os paradigmas tecnológicos definem as oportunidades tecnológicas para inovações posteriores e, ao mesmo tempo, os procedimentos básicos que vão permitir a exploração dessas novidades. As inovações tecnológicas que acompanham os processos de instauração de novos paradigmas possuem uma dinâmica singular e um tipo especial e decisivo de inovação (DOSI, 1984).

Neste contexto, Dosi (1984), ao analisar em detalhe o mecanismo que une a mudança técnica ao sistema socioeconômico - "da grande ciência até a produção" -, lembra 
que, uma vez estabelecido um caminho tecnológico promissor, inaugura-se uma fase de desdobramentos no sentido da instituição de atividades normais de solução de problemas, que vão dando forma ao novo paradigma no plano tecnológico. Porém, a mudança de paradigma não se define integralmente no jogo de interesses imediatos da produção ou, mais amplamente, dos capitalistas. Em outras palavras, constituem-se "trajetórias tecnológicas", umas mais outras menos poderosas no seu papel transformador, conforme o caso. Os diferentes graus de competência tecnológica entre as empresas são conseqüências de características específicas à firma e dependem das mudanças nas trajetórias tecnológicas.

Para Cardoso (2003, p. 64) trajetória tecnológica é "a ação do progresso tecnológico inserido num dado paradigma tecnológico, ou seja, é o modo ou o padrão 'normal' de formular e de procurar soluções para problemas específicos". Esse conceito torna-se interessante no estudo empírico, porque sinaliza a direção tomada pelo progresso técnico, uma vez que os indicadores econômicos, agindo de forma isolada, perdem essa função.

Segundo Dosi (1984, p. 19), o "mecanismo de mercado é particularmente falho na seleção ex-ante de trajetórias tecnológicas, mesmo que opere a contento na orientação posterior da evolução da trajetória selecionada". Partindo deste pressuposto, Galvão (2003) acrescenta que é por este motivo que existem instituições dedicadas a superar a passagem entre a ciência pura e P\&D aplicada.

Para Dosi et al. (2002), a noção de trajetórias tecnológicas está associada com as progressivas realizações das oportunidades inovadoras subjacentes a cada paradigma, trajetórias que podem, em princípio, ser mensuradas em termos de mudanças nas características tecno-econômicas dos "artefatos" e processos de produção.

The core ideas involved in this notion of trajectories are the following: First, each particular body of knowledge (each paradigm) shapes and constraints the rates and direction of technical change, in a first rough approximation, irrespectively of market inducements. Second, technical change is partly driven by repeated attempts to cope with technological imbalances which itself creates. Third, as a consequence, one should be able to observe regularities and in variances in the pattern of technical change which hold under different market conditions (e.g. under different relative prices) and whose disruption is mainly correlated with radical changes in knowledge-bases (in paradigms) Dosi et al. (2002, p. 10).

Uma trajetória tecnológica vai designar o progresso dos conhecimentos tecnológicos em função das arbitragens técnicas e econômicas que são definidas pelos paradigmas. É de supor que as oportunidades de melhoramentos tecnológicos são definidas pelo paradigma, enquanto as trajetórias são em número limitado. Não existe uma infinidade de trajetórias, 
apenas algumas trajetórias possíveis. Por exemplo, tomando-se o caso do motor a combustão houve, primeiro, a elaboração do motor, com base no uso da gasolina para combustão interna. Em seguida, as empresas exploraram as oportunidades tecnológicas relacionadas com a antecipação da evolução da demanda, e foi elaborado o motor a diesel. No Brasil, houve outra trajetória explorada que foi o uso do álcool e que, atualmente, está sendo testado em outros países. O bicombustível - motor que admite a utilização de álcool ou gasolina em qualquer proporção - já é uma realidade para os veículos nacionais.

Para Kupfer (1996, p. 357), no caso da noção formulada por Dosi, de suma importância é o reconhecimento de que um paradigma tecnológico é, mesmo que varie em seus graus, específico de cada tecnologia ou setor, isto é, "é uma tecnologia de mudança técnica", definida pela base de informações resultante do conhecimento formal (científico) ou tácito e da acumulação de capacitações pelos inovadores, através de experiências anteriores que são obviamente idiossincráticas a cada tecnologia e a cada institucionalidade setorial.

De acordo com Albuquerque (1998, p. 69), as oportunidades tecnológicas serão aproveitadas pelas firmas caso as condições de apropriabilidade favoráveis garantam a realização de lucros temporários. Neste sentido, para Gomes (2003), as firmas mais competentes ou líderes tecnológicas estão mais habilitadas para expandir as suas atividades em novos campos ou ambientes e, por conseguinte, mais aptas a obter lucro que venha a compensar os custos financeiros necessários a este movimento.

As mudanças nos paradigmas e o desenvolvimento ao longo das trajetórias tecnológicas são responsáveis pelo surgimento de oportunidades tecnológicas a serem exploradas pelas firmas na busca por lucros (TIGRE, 2005).

\section{CONSIDERAÇÕES FINAIS}

Sumarizando, embora o presente artigo ressalte notas sucintas, as idéias neoschumpeterianas ora enfocadas mostram-se adequadas para avançar, teórica e empiricamente, no debate sobre os determinantes do processo dinâmico de desenvolvimento, da mudança tecnológica e da inovação, fato este também atestado por Shikida (1997), Martins (2004) e Rissardi Júnior (2005). Contudo, é digno de menção o fato de que um arcabouço teórico unívoco, necessário ao entendimento das relações entre a mudança tecnológica, a concorrência interfirmas e a dinâmica econômica, ainda não se verifica na Teoria Econômica. 


\section{REFERÊNCIAS}

ALBUQUERQUE, E. M. Patentes segundo a abordagem neo-schumpeteriana: uma discussão introdutória. Revista de Economia Política. São Paulo, v. 18, n. 4, p. 65-83, out./dez., 1998.

CAMARA, M. R. G. Indústria farmacêutica: grupos estratégicos, tecnologia e regulamentação; a experiência brasileira em debate. 1993. 262 f. Tese (Doutorado) - FEA, USP, São Paulo, 1993.

CARDOSO, C. E. L. Competitividade e inovação tecnológica na cadeia agroindustrial de fécula de mandioca no Brasil. 2003. 188 f. Tese (Doutorado em Ciências) - ESALQ, USP, Piracicaba, 2003.

CASTELLS, M. A sociedade em rede. 5. ed. São Paulo: Paz e Terra, 2001. 617 p.

CORAZZA, R. I.; FRACALANZA, P. S. Caminhos do pensamento neo-schumpeteriano: para além das analogias biológicas. Nova Economia, Belo Horizonte, v. 14, n. 2, p. 127-155, maio/ago. 2004.

CORREIA, P. C.; CÁRIO, S. A. F. Inovação e tecnologia como instrumento de ganhos competitivos e desenvolvimento empresarial. In: ECOPAR, 2, Maringá, 2003. Anais... Maringá: UEM-UEL-UEPG-UNIOESTE-IPARDES, 2003. p. 289-302.

DANTAS, A.; KERTSNETZKY, J.; PROCHNIK, V. Empresa, indústria e mercados. In: KUPFER, D.; HASENCLEVER, L. (Org.). Economia industrial: fundamentos teóricos e práticas no Brasil. Rio de Janeiro: Campus, 2002. Cap. 2, p. 23-41.

DINIZ, C. C. Globalização, escalas territoriais e política tecnológica regionalizada no Brasil. Belo Horizonte: UFMG/Cedeplar, 2001. 34 p. (Texto para discussão n. 168).

DOSI, G. Technical change and industrial transformation: the theory and an application to the semiconductor industry. London: The Macmillan Press Ltd., 1984. 338 p.

DOSI, G. Technological paradigms and technological trajectories: a suggested interpretation of the determinants and directions of technical change. Research Policy, v. 11, n. 3, p. 147162, Jun. 1982.

DOSI, G. The nature of the innovative process. In: DOSI, G.; FREEMAN,C.; NELSON, R.; SILVERBERG, G.; SOETE, L. (Org.). Technical change and economic theory. London: Pinter Publishers, 1988. p. 221-238.

DOSI, G.; ORSENIGO, L.; LABINI, M. S. Technology and the economy. LEM working paper, Sant'Anna School of Advanced Studies, Pisa, n. 18, Aug. 2002. 56 p. Disponível em: <http://www.sssup.it/wplem.html>. Acesso em 14 mar. 2005.

DOSI, G.; PAVITT, K.; SOETE, L. The economics of technical change and international trade. Hemel Hempstead: Harvester Wheatsheaf, 1990. 330 p.

FAGERBERG, J. A layman's guide to evolutionary economics. 2002. Disponível em: $<$ http://folk.uio.no/janf/downloadable_papers/02fagerberg_evolution.pdf $>$. Acesso em: 10 abr. 2005.

FREEMAN, C. Innovation and the strategy of the firm. In: FREEMAN, C. The economics of industrial innovation. Harmondsworth: Penguin Books, 1974. p. 225-282.

FREEMAN, C. The "National System of Innovation" in historical perspective. Revista Brasileira de Inovação. Rio de Janeiro, v. 3, n. 1, p. 15-34, Jan./Jun., 2004. 
FREEMAN, C.; CLARK, J.; SOETE, L. Unemployment and technical innovation. London: Frances Pinter, 1982. 214 p.

GALVÃO, A. C. F. Política de desenvolvimento regional e inovação: lições para o Brasil da experiência européia. 2003. 211 f. Tese (Doutorado em Economia) - IE, UNICAMP, Campinas, 2003.

GOMES, R. A internacionalização das atividades tecnológicas pelas empresas transnacionais: elementos de organização industrial da economia da inovação. 2003. 202 f. Tese (Doutorado em Economia) - IE, UNICAMP, Campinas, 2003.

KUPFER, D. Uma abordagem neo-schumpeteriana da competitividade industrial. Ensaios FEE. Porto Alegre, v. 17, n. 1, p. 355-372, 1996.

LEMOS, C. Inovação na era do conhecimento. In: LASTRES, H. M. M.; ALBAGLI, S. (Org.). Informação e globalização na era do conhecimento. Rio de Janeiro: Campus, 1999. Cap. 5, p. 122-144.

MACIEL, R. C. G. Ilhas de alta produtividade: inovação essencial para a manutenção dos seringueiros nas reservas extrativistas. 2003. 88 f. Dissertação (Mestrado em Desenvolvimento Econômico, Espaço e Meio Ambiente) - IE, UNICAMP, Campinas, 2003.

MARTINS, J. P. Capacidades tecnológicas da Fiasul Indústria de Fios Ltda (ToledoPR). Toledo, 2004. 98p. Dissertação (Mestrado em Desenvolvimento Regional e Agronegócio), CCSA, UNIOESTE, Toledo, 2004.

MOWERY, D.; ROSENBERG, N. The influence of market demand upon innovation: a critical review of some recent empirical studies. In: ROSENBERG, N., Org. Inside the black-box: technology and economics. Cambridge: Cambridge University Press, 1982. p. 193-241.

MYTELKA, L. K.; SMITH, K. Policy learning and innovation theory: an interactive and coevolving process. Research Policy, v. 31, n. 8-9, p. 1467-1479, Dec. 2002.

NELSON, R.; WINTER, S. An evolutionary theory of economic change. 6. ed. Cambridge. Harvard University Press, 1996. 437 p.

POSSAS, M. L. Concorrência schumpeteriana. In: KUPFER, D.; HASENCLEVER, L. (Org.). Economia industrial: fundamentos teóricos e práticas no Brasil. Rio de Janeiro: Campus, 2002. Cap. 17, p. 415-429.

RISSARDI JÚNIOR, D. J. A agroindústria canavieira do Paraná pósdesregulamentação: uma abordagem neoschumpeteriana. 2005. 136 p. Dissertação (Mestrado em Desenvolvimento Regional e Agronegócio) - CCSA, UNIOESTE, Toledo.

ROSENBERG, N. Innovation and Economic Growth. OECD, Paris, 2004. Disponível em: < http://www.oecd.org/dataoecd/55/49/342679.02.pdf>. Acesso em: 20 abr. 2005.

ROSENBERG, N. Inside the black box: technology and economics. Cambridge: Cambridge University Press, 1982. 304 p.

ROSENBERG, N. The direction of technological change. Inducement mechanisms and focusing devices. Economic Development and Cultural Change, v. 18, n. 1, p. 1-24, Oct. 1969.

ROSENBERG, N. Why technology forecasts often fail. The futurist, Bethesda, v. 29, n. 4, p. 16-21, Jul./Aug. 1995. 
SALLES FILHO, S. L. M.; SILVEIRA, J. M. F. J. A teoria da inovação induzida e os modelos de "demand pull": uma crítica com base no enfoque neo-schumpeteriano. In: CONGRESSO BRASILEIRO DE ECONOMIA E SOCIOLOGIA RURAL, 28, 1990, Florianópolis. Anais... Brasília: SOBER, 1990. v. 2. p. 41-60.

SHIKIDA, P. F. A. A evolução diferenciada da agroindústria canavieira no Brasil de 1975 a 1985. 1997. 191 f. Tese (Doutorado em Ciências) - ESALQ, USP, Piracicaba, 1997.

TIGRE, P. B. Paradigmas tecnológicos e teorias econômicas da firma. Revista Brasileira de Inovação. Rio de Janeiro, v. 4, n. 1, p. 187-223, jan./jun., 2005.

WINTER, S. Schumpeterian competition in alternative technological regimes. In DAY, R.; ELIASSON, G. The dynamics of market economies. Amsterdam: Elsevier Science Publishers, 1986. 550 p. 